\title{
Proposal of Design Formulae for Equivalent Elasticity of Masonry Structures Made with Bricks of Low Modulus
}

\author{
Muhammad Ridwan, ${ }^{1}$ Isamu Yoshitake, ${ }^{2}$ and Ayman Y. Nassif ${ }^{3}$ \\ ${ }^{1}$ Department of Civil Engineering, Padang Institute of Technology, Jalan Gajah Mada Kandis Nanggalo, Padang, Indonesia \\ ${ }^{2}$ Department of Civil and Environmental Engineering, Yamaguchi University, Tokiwadai 2-16-1, Ube, Yamaguchi 755-8611, Japan \\ ${ }^{3}$ School of Civil Engineering and Surveying, University of Portsmouth, Portsmouth PO1 3AH, UK \\ Correspondence should be addressed to Muhammad Ridwan; mhd.rid.wan.itp@gmail.com
}

Received 14 August 2016; Revised 20 October 2016; Accepted 20 December 2016; Published 17 January 2017

Academic Editor: Gianmarco de Felice

Copyright (C) 2017 Muhammad Ridwan et al. This is an open access article distributed under the Creative Commons Attribution License, which permits unrestricted use, distribution, and reproduction in any medium, provided the original work is properly cited.

\begin{abstract}
Bricks of low elastic modulus are occasionally used in some developing countries, such as Indonesia and India. Most of the previous research efforts focused on masonry structures built with bricks of considerably high elastic modulus. The objective of this study is to quantify the equivalent elastic modulus of lower-stiffness masonry structures, when the mortar has a higher modulus of elasticity than the bricks, by employing finite element (FE) simulations and adopting the homogenization technique. The reported numerical simulations adopted the two-dimensional representative volume elements (RVEs) using quadrilateral elements with four nodes. The equivalent elastic moduli of composite elements with various bricks and mortar were quantified. The numerically estimated equivalent elastic moduli from the FE simulations were verified using previously established test data. Hence, a new simplified formula for the calculation of the equivalent modulus of elasticity of such masonry structures is proposed in the present study.
\end{abstract}

\section{Introduction}

Brick masonry (BM) is a building construction method in which a two-phase composite material is formed of regularly distributed brick and mortar [1]. Usually, the bricks show higher values for compressive strength and stiffness than the mortar. However, the opposite is true in some of the developing countries. For example, the mechanical properties of bricks in some areas of Indonesia show significantly lower values than those of mortar because construction materials are sometimes manufactured in family-run industries [2]. In spite of the use of low-quality bricks, the design code for masonry structures in Indonesia (SNI-2094-2000) is based on the design code of other countries, namely, the DIN 105 standard of Germany and the ASTM C 67-94 standard of the USA.

Hence, most investigations are focused on bricks showing higher strength and when compared to the mortar used in masonry structures. However, as mentioned above, this is not always the case $([2,3])$ in some developing countries. It was reported in [2] that bricks in Payakumbuh, located in the West Sumatera Province of Indonesia, had a significantly low compressive strength of $2.9 \mathrm{MPa}$ on an average. Similarly, Putri [4] reported a brick strength of $2.5 \mathrm{MPa}$ in Padang city. Elhusna et al. [5] observed that the compressive strength of bricks in Bengkulu Province was within the range of 2.46.7 MPa. Wisnumurti et al. [6] investigated the strength of bricks from four different areas in East Java. According to their investigations, the compressive strength was within the range of $0.55-0.9 \mathrm{MPa}$, and the modulus of elasticity of the low-quality bricks was within the range of $279-571 \mathrm{MPa}$. In addition, Basoenondo [7] reported that the compressive strength and the modulus of elasticity of bricks in the West Java Province were $0.5-2.87 \mathrm{MPa}$ and $220-540 \mathrm{MPa}$, respectively. It is noteworthy that the test was based on the American standard ASTM E-111 owing to the lack of an Indonesian standard for the evaluation of the elastic modulus of bricks.

General-purpose bricks in western countries have higher strength and stiffness than mortar, as discussed by [3]. They reported that bricks in India have a relatively lower strength (3-20 MPa) and elastic modulus (300-15000 MPa). Similarly [7], Indonesian bricks have lower strength and stiffness. 
The general theory is based on the assumption that mechanical properties of brick elements are higher than those of mortar (Paulay and Priestly [8]). In most cases, the ideal elasticity used in the design refers to formulae specified in overseas regulation. These assumptions may result in inappropriate design for the construction of masonry structures using Indonesian bricks.

Finite element (FE) simulations are often used to analyze and design such masonry structural systems. The challenges in numerical modeling of the behavior of large-scale masonry systems have led to the development of techniques such as homogenization [22]. Lourenço et al. [22] reviewed the recent trends in homogenization techniques. They discussed different homogenization techniques available in published literature, and special attention was paid to the micromechanicalbased model and the one based on polynomial expansion of the microstress field.

The homogenization techniques are based on establishing constitutive relations in terms of averaged stresses and strains from the geometry and constitutive relations of the individual components. The popularity of such techniques has increased in the masonry community during the last decade $([1,12,14$, 15, 21-25]).

The techniques of masonry homogenization can be classified into three types: traditional homogenization, numerical homogenization, and micromechanical and microstructural models. Pande et al. [14], Hendry [26], and Pietruszczak and Niu [21] used the traditional homogenization with an empirical approach to estimate the volume ratio effects on the physical and the mechanical properties of bricks and mortar. Equivalent elastic properties were determined for a brick-mortar system made with equally spaced layers. In addition, a simplified geometry to represent the complex geometry of the representative cell was adopted so that a close-form solution to the homogenization problem would be possible. This method is suitable for modeling the linear elastic behavior and for a relatively simple modeling of the nonlinear behavior of masonry structures.

Anthoine [15], Mistler et al. [19], Pegon and Anthoine [23], Luciano and Sacco [24], Ma et al. [1], Zucchini and Lourenço [12], and Anthoine [25] developed the numerical homogenization theory, which is applicable to FE simulations of masonry wall structures. It is used to apply the homogenization theory for masonry wall consisting of the periodic arrangement of unit and mortar as cell. Owing to the complexity of a masonry basic cell, it is necessary to use the finite element method to obtain a numerical solution to problems. This approach is suitable for analyzing the nonlinear behavior of the complex masonry basic cell by solving the problem for all possible macroscopic loading histories.

Luciano and Sacco [24], Ma et al. [1], and Zucchini and Lourenço [12] proposed a theory based on the micromechanical and macrostructural concepts. Their model contained representative volume elements and constitutive elements for all geometries. Although this approach is very useful, its applications are limited because it is difficult to determine several parameters in the micromechanical model for macroscopic analysis.
TABLE 1: Moduli of elasticity for homogenization.

\begin{tabular}{lcc}
\hline Author(s) & $E_{\text {brick }}(\mathrm{MPa})$ & $E_{\text {mortar }}(\mathrm{MPa})$ \\
\hline Stefanou et al. [9] & 6740 & 1700 \\
Cluni and Gusella [10] & 12500 & 1200 \\
Cecchi and Di Marco [11] & 1000 & $E_{\text {mor }} / E_{b}<1$ \\
Zucchini and Lourenço [12] & 20000 & $1<E_{b} / E_{\text {mor }}<1000$ \\
Rekik et al. [13] & 10000 & 0.49 \\
Pande et al. [14] & 11000 & $E_{b} / E_{\text {mor }}=1.1-11$ \\
Anthoine [15] & 11000 & 2200 \\
Lee et al. [16] & 22000 & 7400 \\
Gabor et al. [17] & 13000 & 4000 \\
Lourenço [18] & 20000 & 2000 \\
\hline
\end{tabular}

Homogenization typically has two different models, namely, discrete and continuum models. Mohebkhah et al. [27] used discrete models for nonlinear static analysis. They performed simulations using the model for analyzing the fracture behavior of small laboratory panels and verified the model with experimental data. Lourenço et al. [28] used continuum models to analyze masonry structures. The model is appropriate for analyzing anisotropic elastic and inelastic behaviors; it is also suitable for nonlinear static analysis, such as in case of large-scale masonry walls.

The generalization of the homogenization procedure for out-of-plane behavior of masonry [29] can be applied to periodic composite materials. There are two or more units of masonry, such as stones, bricks, and hollow bricks. Mistler et al. [19] examined the effect of the elastic properties on a brick masonry structure. They used the numerical homogenization technique to confirm the effectiveness of the generalization of the homogenization procedure. Pegon and Anthoine [23] developed a homogenization theory for studying the macroscopic nonlinear behavior of masonry. Lourenço [18] used a micromechanical model of homogenization for threedimensional numerical simulations. The study developed a representative volume element system using multiparametrical representations of the elastic properties of masonry. It was observed that typical mortar has a lower elasticity than bricks in the homogenization process (Table 1).

The purpose of the present study is to numerically determine the equivalent elastic modulus of a brick masonry construction, assuming that the elastic modulus of mortar $\left(E_{\text {mor }}\right)$ is higher than that of bricks $\left(E_{b}\right)$. The analysis in the present study was based on a numerical simulation using the homogenization technique. The fundamental model is a twodimensional (2D) representative volume element (RVE) formulation. The proposed analytical approach can significantly contribute to a safer analysis and design of masonry structural systems built with low-quality bricks in various developing countries, such as Indonesia.

\section{Approach of the Solution}

2.1. Representative Element. The representative volume element (RVE) is a typical unit of masonry; it was selected to represent brick masonry. We considered a masonry wall $\Omega$, 
consisting of a periodic arrangement of masonry units and mortar joints, as shown in Figure 1 . The periodicity allows $\Omega$ to be regarded as the repetition of the RVE [22].

Ma et al. [1] stated that a masonry RVE should include all the participating materials, constitute the entire structure in a periodic and continuous distribution, and be the minimum unit satisfying the first two conditions.

The RVE cell is classified into two types: RVE-1 and RVE2. The cell dimensions of these two types of cells are the same; however, the arrangement of bricks and mortar in the cells are different. Ma et al. [1] compared both RVEs and observed that their stress-strain curves under the condition of vertical compression without applying horizontal restrains are the same. Figure 1 shows an RVE. It provides a valuable dividing boundary between the discrete and continuum models. Equivalent stress-strain relations of the RVE were homogenized by applying a compatible, distributed displacement loading along the vertical and horizontal directions and a positive-negative horizontal displacement loading on the top and bottom of the RVE surfaces [1].

The average stress and strain can be calculated via the following equations:

$$
\begin{gathered}
\bar{\sigma}_{i j}=\frac{1}{|\Omega|} \int_{\Omega} \sigma_{i j} d \Omega, \\
\bar{\varepsilon}_{i j}=\frac{1}{|\Omega|} \int_{\Omega} \varepsilon_{i j} d \Omega,
\end{gathered}
$$

where $\Omega$ is volume of the RVE cell.

The elastic parameters of the RVE can be derived from the simulated stress-strain relation.

2.2. Constitutive Equation. Isotropic, linear elastic materials were used for both the brick and mortar. The constitutive stress-strain relations are presented in the following matrix:

$$
\left\{\begin{array}{c}
\sigma_{x} \\
\sigma_{y} \\
\tau_{x y}
\end{array}\right\}=\frac{E}{1-v^{2}}\left[\begin{array}{ccc}
1 & v & 0 \\
v & 1 & 0 \\
0 & 0 & \frac{1-v}{2}
\end{array}\right]\left\{\begin{array}{c}
\varepsilon_{x} \\
\varepsilon_{y} \\
\gamma_{x y}
\end{array}\right\} .
$$

Here, $E$ and $v$ are Young's modulus and Poisson's ratio, respectively, which were applied for each material, individually. Five independent material properties $\left(E_{x}, E_{y}, v_{x}, v_{y}\right.$, and $\left.G\right)$ are used to constitute the equation for the isotropic material under the plane stress condition, which is expressed as

$$
\left\{\begin{array}{l}
\bar{\sigma}_{x x} \\
\bar{\sigma}_{y y} \\
\bar{\tau}_{x y}
\end{array}\right\}=\left[\begin{array}{ccc}
\frac{\bar{E}_{11}}{1-\bar{v}_{12} \bar{v}_{21}} & \frac{\bar{E}_{11} \bar{v}_{21}}{1-\bar{v}_{12} \bar{v}_{21}} & 0 \\
\frac{\bar{E}_{22} \bar{v}_{12}}{1-\bar{v}_{12} \bar{v}_{21}} & \frac{\bar{E}_{22}}{1-\bar{v}_{12} \bar{v}_{21}} & 0 \\
0 & 0 & \bar{G}
\end{array}\right]\left\{\begin{array}{c}
\bar{\varepsilon}_{x x} \\
\bar{\varepsilon}_{y y} \\
\bar{\gamma}_{x y}
\end{array}\right\} .
$$

The effective properties of the brick masonry structure can be calculated from (3), and a set of numerical solutions were derived under certain boundary conditions. The numerical simulation results were combined using a nonlinear regression process.

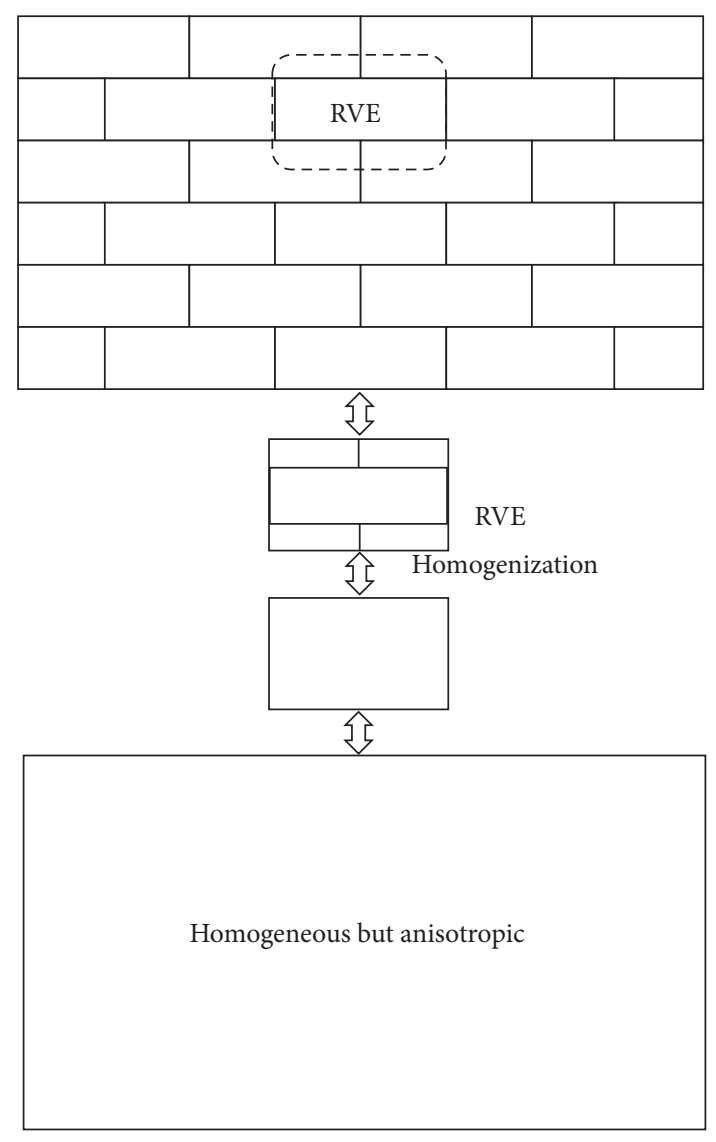

FIGURE 1: Homogenization of masonry material.

\section{Numerical Simulations}

3.1. Simulation Model. The physical models of the RVEs (RVE-1 and RVE-2) used in the present numerical simulation are shown in Figure 2. Both were used to obtain the differences in elasticity, Poisson's ratio, and shear moduli between the RVE-1 and RVE-2. For each RVE cell, three boundary conditions (BCs) and a displacement load were applied; the FE simulation was realized through the FE program SAP2000-V17. The three BCs will be explained in Section 3.3. Then, the values of $E, v$, and $G$ were calculated using (4)-(7). The elasticity and Poisson's ratio were used as baseline data, and various data measurements for elasticity were obtained from the FE simulation.

Figure 3 shows the quadrilateral (Q4) finite element with four nodes and eight degrees of freedom (DOF) used to discretize the problem in the numerical investigation.

The RVE-1 and RVE- 2 cells consisted of 3,360 elements, 3,485 nodes, and 6,970 DOF. The brick and the mortar were discretized individually. The dimensions of the cell were 250 $\times 120 \times 65 \mathrm{~mm}$, and the assumed thickness of the mortar was $15 \mathrm{~mm}$.

Ma et al. [1] also applied both the models and obtained the same numerical results. The numerical results in the present study indicated that the RVE was able to represent the material properties at the unit volume level. Thus, all 


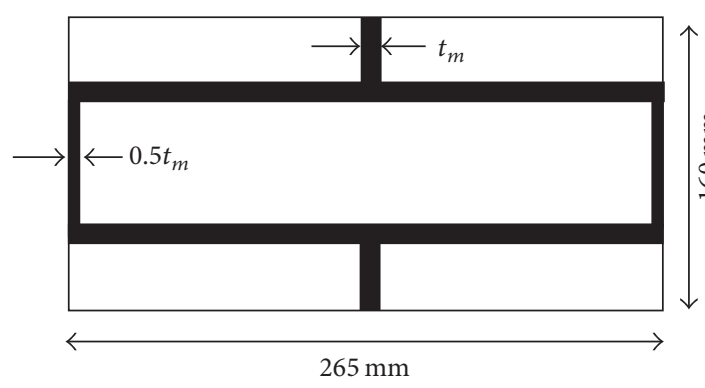

(a)

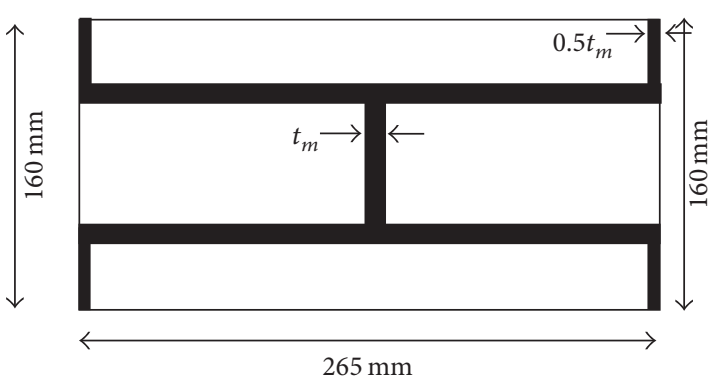

(b)

FIgUre 2: Model of masonry cells: (a) RVE-1; (b) RVE-2.

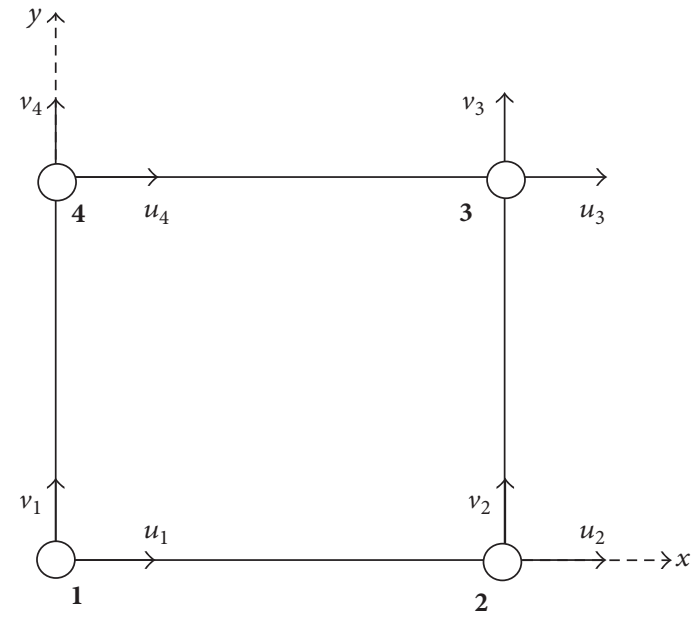

FIGURE 3: Finite element Q4 used in numerical analysis.

TABLE 2: Material parameter for brick and mortar.

\begin{tabular}{lccc}
\hline Material & $\begin{array}{c}E_{x}=E_{y} \\
(\mathrm{MPa})\end{array}$ & $v_{x}=v_{y}$ & $\begin{array}{c}G=E / 2(1+\nu) \\
(\mathrm{MPa})\end{array}$ \\
\hline Brick & 11000 & 0.2 & 4580 \\
Mortar & 2200 & 0.25 & 880 \\
\hline
\end{tabular}

$E_{x}, E_{y}=$ Young's modulus [MPa], $G=$ Kirchhoff's modulus [MPa], $v_{x}, v_{y}=$ Poisson's ratios.

subsequent calculations were performed with the RVE-1 model as the RVE.

3.2. Materials. The material properties for the validation of the model were obtained from the experimental and simulation results published by Pegon and Anthoine [23] and $\mathrm{Ma}$ et al. [1] (Table 2). These material properties are used to ensure applying FE program for the RVE model. Then, the material properties of mortar have higher and lower elasticity than the brick which can be used to the simulation.

3.3. Boundary Condition. Ma et al. [1] simulated various BCs. Three state groups of BCs were applied to the RVE model. These included the compression-compression stress state, the compression-tension state, and the compression-tensionshear stress state. Each group had six BC cases. Ma et al. [1] stated that the elastic modulus could be obtained from the abovementioned groups using three $\mathrm{BC}$ cases. Figure 4 shows the three load cases and the boundary displacements that were used in present study. There were certain displacement boundary conditions: (1) $u \neq 0, v=0, \bar{\varepsilon}_{x x} \neq 0, \bar{\varepsilon}_{y y}=0$, and $\bar{\gamma}_{x y}=0$ were used for horizontal compression, (2) $v \neq 0$, $u=0, \bar{\varepsilon}_{y y} \neq 0, \bar{\varepsilon}_{x x}=0$, and $\bar{\gamma}_{x y}=0$ were used for vertical compression, and (3) $u \neq 0, \mathrm{v}=0, \bar{\varepsilon}_{x x}=0, \bar{\varepsilon}_{y y}=0$, and $\bar{\gamma}_{x y} \neq 0$ were used for horizontal shear. A displacement of approximately $0.05 \mathrm{~mm}$ was applied to the nonzero side of the cell. The zero-displacement side was constrained to achieve simplicity in calculations and homogenization of the linear static materials.

3.4. Equivalent Elastic Modulus Calculation. The average values of stress and strain can be calculated by employing (1) as well as the FE simulation results. The effective material parameters of the masonry structure can be estimated as these for an equivalent, homogeneous orthotropic material by using (4)-(7) [1]:

$$
\begin{aligned}
\bar{v}_{y x} & =\frac{\bar{\sigma}_{x x}{ }^{(2)}}{\bar{\sigma}_{y y}{ }^{(2)}}, \\
\bar{v}_{x y} & =\frac{\bar{\sigma}_{y y}{ }^{(1)}}{\bar{\sigma}_{x x}{ }^{(1)}}, \\
\bar{E}_{x x} & =\frac{\bar{\sigma}_{x x}{ }^{(1)}\left(1-\bar{v}_{x y} \bar{v}_{y x}\right)}{\bar{\varepsilon}_{x x}{ }^{(1)}} \\
& =\bar{\sigma}_{x x}{ }^{(1)} \frac{1-\left(\bar{\sigma}_{x x}{ }^{(2)} / \bar{\sigma}_{y y}{ }^{(2)}\right)\left(\bar{\sigma}_{y y}{ }^{(1)} / \bar{\sigma}_{x x}{ }^{(1)}\right)}{\bar{\varepsilon}_{x x}{ }^{(1)}}, \\
\bar{E}_{y y} & =\frac{\bar{\sigma}_{y}{ }^{(2)}\left(1-\bar{v}_{x} \bar{v}_{y}\right)}{\bar{\varepsilon}_{y}{ }^{(2)}} \\
& =\bar{\sigma}_{x x}{ }^{(2)} \frac{1-\left(\bar{\sigma}_{x x}{ }^{(2)} / \bar{\sigma}_{y y}{ }^{(2)}\right)\left(\bar{\sigma}_{y y}{ }^{(1)} / \bar{\sigma}_{x x}{ }^{(1)}\right)}{\bar{\varepsilon}_{y y}{ }^{(2)}}, \\
\bar{G} & =\frac{\bar{\tau}_{x y}{ }^{(3)}}{\bar{\gamma}_{x y}{ }^{(3)}} .
\end{aligned}
$$




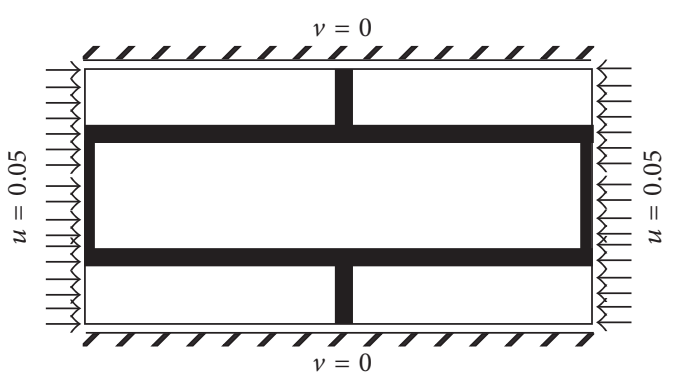

(a)

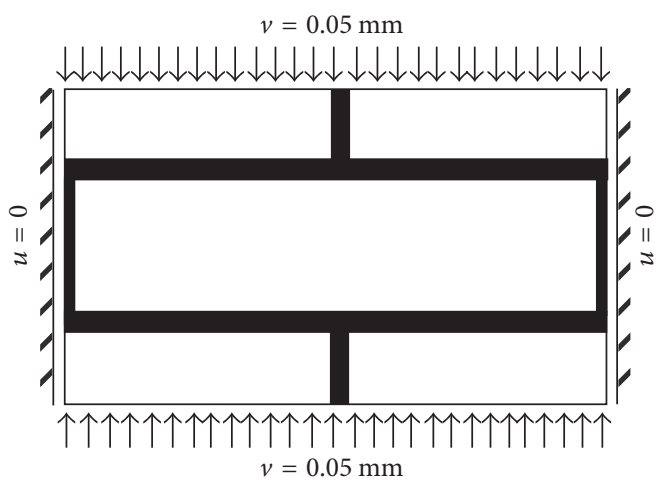

(b)

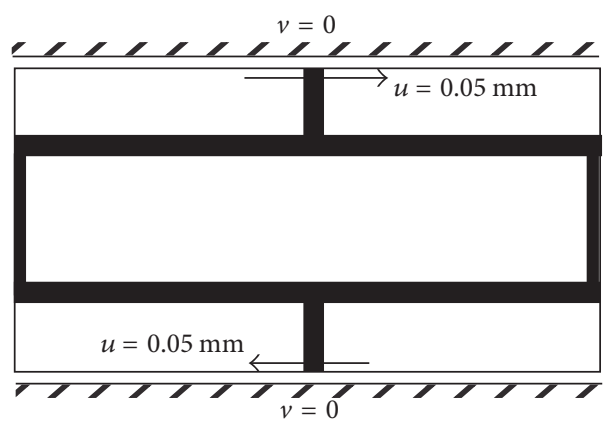

(c)

FIGURE 4: Load cases of imposed boundary displacement: (a) load case 1: horizontal compression; (b) load case 2: vertical compression force; (c) load case 3: horizontal shear force.

The superscript index $(i=1,2)$ denotes the BC case. Subsequently, the simulations were performed with a wide range of elasticity and Poisson's ratio values. Then, nonlinear regression was applied to determine the trend line of the simulation and the basis of the formulation. The formula can represent the case $E_{\text {mor }}>E_{b}$ as well as the case where $E_{\text {mor }}<E_{b}$. The equivalent elastic modulus is the average value of $E_{x x}$ and $E_{y y}$ in the simulation (see (5) and (6)).

To ensure the accuracy of the results, the validation and verification were performed by comparing the results with the numerical and experimental results obtained in other research works $[1,19,30]$. The simulation results were analyzed to develop the empirical formula proposed in this work.

\section{Results and Discussion}

4.1. Equivalent Elastic Modulus. In this study, the elasticity values of the brick are 1,000 $\mathrm{MPa}, 2,000 \mathrm{MPa}, 5,000 \mathrm{MPa}$, and $10,000 \mathrm{MPa}$. The elasticity values of mortar are 0.2 to 5 times the elasticity of the brick. Poisson's ratio was assumed to be 0.25 , where $v_{x}=v_{y}$. Each of these data was applied to every load case (RVE-1 and RVE-2).

The elastic modulus of the mortar and brick are the main input data in the numerical simulation. The ratio of the elastic modulus of mortar to that of the brick is called the ratio of mortar $\left(R_{\text {mor }}\right)$. The value of $R_{\text {mor }}$ changes depending on the elasticity of both the materials, bricks, and mortar, in the unit cell.
Additionally, the value of $R_{\text {mor }}$ was also influenced by the dimensions of the two elements. The Indonesian code for masonry (SNI 15-2094-2000) regulates the dimensions of bricks with diverse sizes, which are $65 \pm 2$ to $80 \pm 3 \mathrm{~mm}$ in height, $92 \pm 2$ to $110 \pm 2 \mathrm{~mm}$ in width, and $190 \pm 4$ to $230 \pm 5 \mathrm{~mm}$ in length. Changes in the thickness of either the brick or mortar $t$ affect the value of $R_{\text {mor }}$. Here, the thickness of the mortar is set to $t_{m} \leq 0.5 h_{b}$, where $h_{b}$ is the thickness of brick. Therefore, by using a mortar thickness of $0.5 h_{b}$, the ratio of the volume of the mortar would reach its maximum value. It could reach up to $47 \%$ if volume of mortar divided by RVE unit when the dimensions of bricks are $h_{b}=65 \mathrm{~mm}$, $l_{b}=250 \mathrm{~mm}$, and $w_{b}=110 \mathrm{~mm}$.

The change in the volume ratio influences the stress-strain distribution in the unit cell.

Therefore, it will affect the value of Poisson's ratio and that of the equivalent elasticity of the masonry structure. Thus, for the case $E_{\text {mor }}>E_{b}$ or $R_{\text {mor }}>1$, higher mortar elasticity increases the equivalent elastic modulus of the masonry structure.

Figure 5 shows the simulation results and regression curves between the $R_{\text {mor }}$ and $E_{m}$ where $E_{m}$ is the equivalent elastic modulus of the masonry structure. It is remarkable that the coefficient of correlation is established at a value of 0.9974. The best equation of $R_{\text {mor }}$ is power trend line with the power value is 0.2798 . This value did not change for various $E_{b}$; however, there is only a slight difference in the elasticity value of the brick. Based on the results, the proposed 


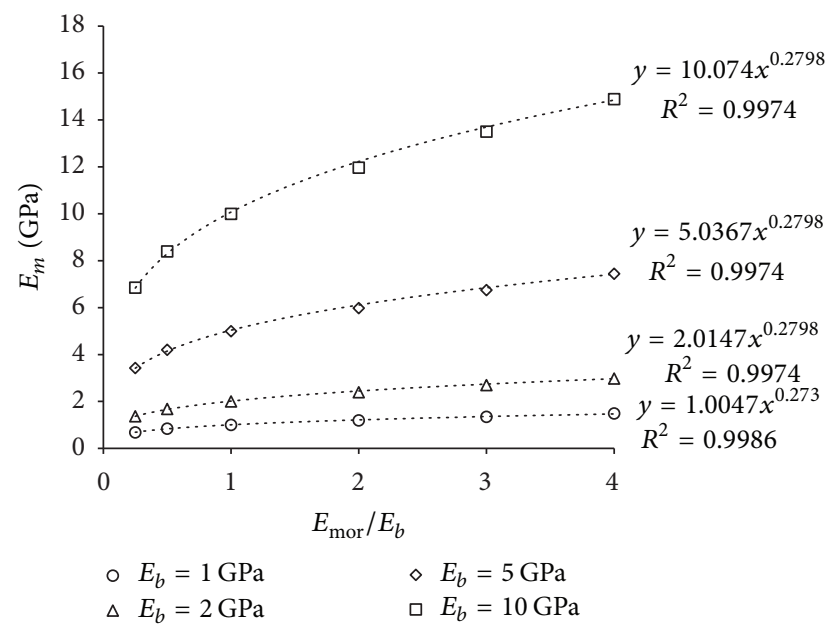

FIGURE 5: Simulation results of equivalent elastic moduli of brick masonry.

equations for the equivalent elastic modulus in the simulation are presented as follows:

$$
E_{m}=E_{b}\left(R_{\mathrm{mor}}\right)^{\delta+\theta}
$$

where $R_{\text {mor }}=E_{\text {mor }} / E_{b}$.

The superscript $\delta$ denotes the geometric properties of the cells and $\theta$ is a disparity value from the geometric properties to the ratio of the elastic modulus of mortar.

The value $\delta$ is given by the following equation:

$$
\delta=0.33\left(\rho_{\text {mor }}+\bar{v}+\frac{t_{m}}{h_{b}}\right),
$$

where $\rho_{\text {mor }}$ is the volume ratio of mortar to the area of the cell, $\rho_{\text {mor }}=t_{m}\left(t_{m}+h_{b}+l_{b}\right) /\left(t_{m}\left(t_{m}+h_{b}+l_{b}\right)+\left(h_{b} l_{b}\right)\right) ; \bar{v}$ is the average Poisson's ratio (brick and mortar); $\bar{v}=0.5\left(v_{\text {mor }}+v_{b}\right)$; $t_{m} / h_{b}$ is the ratio of the thickness of the mortar to that of the brick

The disparity value $\theta$ can be calculated as follows:

If $R_{\text {mor }}>1$, the following expression can be used:

$$
\theta=0.002\left(R_{\mathrm{mor}}^{2}+R_{\mathrm{mor}}+1\right) \text {. }
$$

If $R_{\text {mor }}<1$, the following expression can be used:

$$
\theta=0.002\left(\left(\frac{1}{R_{\mathrm{mor}}}\right)^{2}+\frac{1}{R_{\mathrm{mor}}}+1\right) .
$$

The simulation results obtained from using this formula are suitable for cases of ratios from 0.2 to 5.0. Figure 5 shows simulation results using brick elasticity values of $1,2,5$, and $10 \mathrm{GPa}$. The result confirms that the elasticity of the masonry structure increases in accordance with the mortar ratio $R_{\text {mor }}$. Figure 5 also shows that the gradient of each curve is different for each $R_{\text {mor }}$.

The percentage of change (Poc) was applied to quantify the changes of gradient in each curve. The Poc is an index of how much a quantity has increased or decreased with respect to the original amount. Therefore, the Poc can be obtained from

$$
\operatorname{Poc}=\frac{E_{m}-E_{b}}{E_{b}} 100 \%
$$

Table 4 provides the percentage of change for the curves in Figure 5, where for any change in $R_{\text {mor }}$ for each $E_{b}$, it remains the same. To obtain the equivalent elastic modulus of the masonry structure with a different gradient, (13) can be employed:

$$
E_{m,(\mathrm{poc})}=E_{b}(1+\mathrm{Poc}) \text {. }
$$

This illustrates that the elasticity of the masonry structure will increase linearly with an increase in $R_{\text {mor }}$ for each $E_{b}$. Table 5 lists some examples of $E_{m}$. The results indicate that the gradient for each value of $E_{b}$ and $R_{\text {mor }}$ is different, but at the same $R_{\text {mor }}$, the Poc is the same. This indicates that an increase in the $R_{\text {mor }}$ value influences the stress distribution of the elements in the cells and increases the equivalent elastic modulus of the masonry structure. Conversely, a decrease in the elasticity of mortar would minimize the equivalent elastic modulus of the masonry structure. From the above discussion, we can conclude that it is beneficial to increase the elasticity of the bricks if the elasticity of mortar is higher than the elasticity of the bricks.

4.2. Poisson's Ratio and Shear Modulus. Poisson's ratio describes the transverse strain; therefore, it is obviously related to shear. The shear modulus, usually abbreviated as $G$, plays the same role in describing shear as Young's modulus does in describing the longitudinal strain. It is defined as $G=$ shear stress/shear strain.

The shear modulus $G$ can be calculated in terms of $E$ and $v: G=E / 2(1+v)$. As $v$ ranges from $1 / 4$ to $1 / 3$ for most rocks, therefore that $G$ is approximately calculated as $0.4 E$.

The average Poisson's ratio decreased linearly as the $R_{\text {mor }}$ value increased. The $t$ equivalent Poisson's ratio can be expressed as follows.

If $R_{\text {mor }}<1$, the following expression can be used:

$$
\bar{v}_{m}=\bar{v}-0.015\left(\frac{1}{R_{\text {mor }}}\right) .
$$

If $R_{\text {mor }}>1$, the following expression can be used:

$$
\bar{v}_{m}=\bar{v}-0.015 R_{\text {mor }}
$$

Poisson's ratio of the masonry structure decreased by approximately 0.015 times the $R_{\text {mor }}$ value owing to the assumption that Poisson's ratio of the brick is smaller than that of mortar.

In present study, the shear modulus was obtained from the simulation results using (7). The range of the estimated $G$ was $60-70 \%$ of $E_{m}$ because of the lower Poisson's ratio estimated in the simulation.

The vertical deformation ( $y$ direction) and the lateral deformation ( $x$ direction) are different owing to Poisson's effect. The effect may lead to the increase of the equivalent 
$\bar{G}$. Using (14) and (15), the equivalent shear modulus $\bar{G}$ can be expressed as in

$$
\bar{G}=\frac{E_{m}}{1.3(1+\bar{v})} .
$$

4.3. Verification and Validation. The numerical simulation results were compared to the results of the simulation conducted by Wang et al. [20], Ma et al. [1], and Mistler et al. [19], as given in Table 3. It is evident that the 2D plane stress analysis results reported by Mistler et al. [19] are similar to those in the present work. However, $\bar{E}_{y}, \bar{v}_{y}$, and $\bar{G}$ present slight differences because the input data used were different. It should be noted that the average horizontal elastic modulus of the masonry structure was greater than that in the vertical direction. The calculated average value of the equivalent elasticity agreed very well with the experimental data obtained by Mistler et al. [19] on the 2D plane stress and by and $\mathrm{Ma}$ et al. [1]. By employing the same input data, listed in Table 2, the value of $\bar{E}_{x}$ is equal to Mistler's result and slightly different from Ma's result. The differences in the results value range are $7.5 \%$ while the value of Poisson's ratio $v_{x}$ is relatively similar. The value of $G$ is different and is slightly increase, because of the diminution of Poisson's ratio value.

4.4. Formula Comparison. In the previous investigations, many formulae have been proposed for the determination of material parameters. These formulae addressed isotropic materials. Zavalis et al. [30] have cited some formulae developed by Matysek [1999] (such as (17)), Brooks [1999] (see (18)), and Ciesielski [1999] (see (19)). However, they were originally derived to be used in the modeling of masonry structures. It is noteworthy that the values of elastic moduli obtained from other researchers are similar to the results obtained in the numerical simulations reported in the present study

$$
E_{m}=\frac{1.25 \xi+1}{1.25 \xi+\beta} E_{b}
$$

where $\xi$ is the ratio of the height of bricks to the thickness of the mortar joints and $\beta$ is the ratio of brick's elastic modulus to that of the mortar

$$
\frac{1}{E_{m}}=\frac{0.86}{E_{b}}+\frac{0.14}{E_{\text {mor }}}
$$

where $E_{b}$ and $E_{\text {mor }}$ are the elastic moduli of the bricks and mortar, respectively,

$$
E_{m}^{i}=\frac{1.20 E_{b}^{i} E_{\mathrm{mor}}^{i}}{0.2 E_{b}^{i}+E_{\mathrm{mor}}^{i}}
$$

where $E_{b}^{i}$ and $E_{\text {mor }}^{i}$ are the medium elastic moduli of the brick and mortar in section $i$, respectively.

The equivalent elasticities $\left(E_{m}\right)$ estimated through the proposed formula were compared to the modulus derived from the previous formulae, (17)-(19). Figure 6 shows that

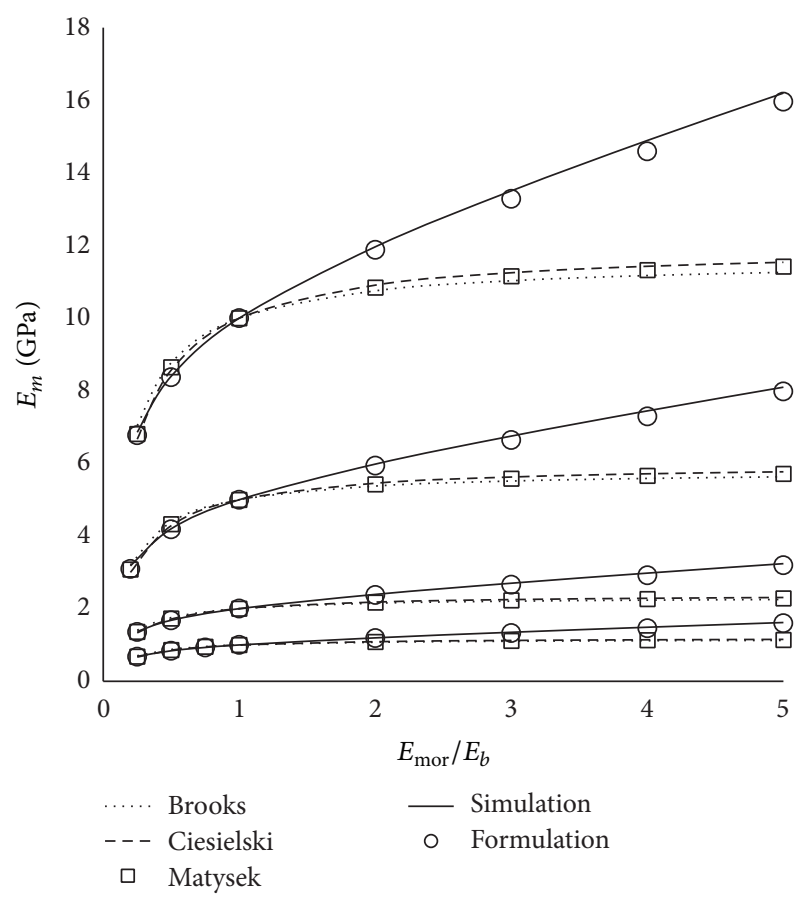

FIGURE 6: Equivalent elasticity of brick masonry.

these previous formulae underestimate the equivalent elasticity of the masonry structures with low-modulus bricks. It is noteworthy that the proposed formula is applicable for the elasticity ratio of $R_{\text {mor }}<1$.

Equations (17)-(19) have a Poc behavior similar to that of the simulation results (Table 4). There same percentage of change can be observed for any $E_{b}$, as presented in Table 6 . However, there are differences for the case of $R_{\text {mor }}>1$. By using (17)-(19), when $R_{\text {mor }}=2$, the $E_{m}$ value has only increased by approximately $7.53 \%$ to $9.09 \%$ and for $R_{\text {mor }}=5$, the $E_{m}$ value has increased by approximately $12.6 \%$ to $15.38 \%$. For the case of $R_{\text {mor }}=2, E_{m}$ increased by approximately 19.48 $19.79 \%$, and when $R_{\text {mor }}=5, E_{m}$ increased by approximately $61.68-62.71 \%$.

For $R_{\text {mor }}<1$, the Poc presents similar values between the proposed and the previous formulae, particularly with the Ciesielsky and Matysek formula; however, there was a slight difference with respect to the Brooks formula. This indicates that for the case of $R_{\text {mor }}<1$, the proposed formula can be used as well.

Any increase in the ratio of mortar increased the elasticity of masonry. This is consistent with the data obtained by Drougkas et al. [31] and Gumaste et al. [3] who also examined the $E_{\text {mor }}>E_{b}$ case as shown in Table 6.

Table 8 and Figure 7 illustrate the comparison results of the equivalent elastic moduli based on data obtained by Gumaste et al. [3] (see Table 7). Table 8 and Figure 7 also demonstrate a comparison between the equivalent elastic moduli results derived from the proposed formula to those derived from the formulae proposed by Gumaste, Brooks, Matystek, and Ciesielsky.

Results from the Gumaste formula were almost similar to the simulation; the difference was lower than $1 \%$. On the 
TABLE 3: Homogenization model result from various researcher.

\begin{tabular}{|c|c|c|c|c|c|}
\hline Model (MPa) & $\bar{E}_{x}$ & $\bar{E}_{y}$ & $\bar{v}_{x}$ & $\bar{v}_{y}$ & $\bar{G}\left(0.4 \bar{E}_{m}\right)$ \\
\hline \multicolumn{6}{|l|}{ This research } \\
\hline RVE-2 & 7882 & 6120 & 0.1600 & 0.2046 & $4520(2450)$ \\
\hline RVE-1 & 7882 & 6121 & 0.1604 & 0.2044 & $4441(2450)$ \\
\hline Ma et al. [1] & 7899 & 6274 & 0.270 & 0.310 & 2884 \\
\hline \multicolumn{6}{|l|}{ Mistler et al. [19] } \\
\hline 3D model & 7958 & 6777 & 0.164 & - & 2583 \\
\hline 2D Plane Stress & 7882 & 6592 & 0.159 & - & 2682 \\
\hline 2D generalized plane strain & 7971 & 6811 & 0.165 & - & 2584 \\
\hline 2D plane strain & 8157 & 6963 & 0.194 & - & 2584 \\
\hline \multicolumn{6}{|l|}{ Wang et al., [20] } \\
\hline FEM, stack bond [15] & 8530 & 6790 & 0.196 & - & 2580 \\
\hline FEM, running bond [15] & 8620 & 6770 & 0.2 & - & 2620 \\
\hline Periodic model stack bond & 8568 & 6850 & 0.191 & - & 2594 \\
\hline Periodic model stack bond & 8574 & 6809 & 0.197 & - & 2620 \\
\hline Periodic model running bond & 8574 & 6809 & 0.197 & - & 2620 \\
\hline Multilayer method [14] & 8525 & 6906 & 0.208 & - & 2569 \\
\hline Wo-step method [21] & 9,187 & 6,588 & 0.215 & - & 2658 \\
\hline
\end{tabular}

TABLE 4: Percentage of change of simulation.

\begin{tabular}{|c|c|c|c|c|c|c|}
\hline \multicolumn{7}{|c|}{ Percentage of change (Poc)\% } \\
\hline \multirow{2}{*}{$E_{b}(\mathrm{MPa})$} & \multicolumn{6}{|c|}{$R_{\text {mor }}$} \\
\hline & 0.25 & 0.5 & 1 & 2 & 3 & 4 \\
\hline 1000 & -31.42 & -15.98 & 0 & 19.62 & 35.05 & 61.98 \\
\hline 2000 & -31.42 & -15.98 & 0 & 19.62 & 35.05 & 61.98 \\
\hline 5000 & -31.42 & -15.98 & 0 & 19.62 & 35.05 & 61.98 \\
\hline 10000 & -31.42 & -15.98 & 0 & 19.62 & 35.05 & 61.98 \\
\hline
\end{tabular}

TABLE 5: Examples of the calculations $E_{m}$.

\begin{tabular}{|c|c|c|c|c|}
\hline Case & $R_{\text {mor }}$ & Poc (\%) & $E_{b}(\mathrm{MPa})$ & $\begin{array}{c}\text { Calculation } \\
E_{m}=E_{b} \times(1+\text { Poc } \%) \mathrm{MPa}\end{array}$ \\
\hline \multirow{3}{*}{$R_{\text {mor }}>1$} & 4 & 61.98 & $\begin{array}{c}1000 \\
2000 \\
5000 \\
10000\end{array}$ & $\begin{array}{l}1620 \\
3240 \\
8099 \\
1698\end{array}$ \\
\hline & 3 & 35.05 & $\begin{array}{c}1000 \\
2000 \\
5000 \\
10000\end{array}$ & $\begin{array}{c}1351 \\
2701 \\
6753 \\
13505\end{array}$ \\
\hline & 2 & 19.62 & $\begin{array}{c}1000 \\
2000 \\
5000 \\
10000\end{array}$ & $\begin{array}{c}1196 \\
2392 \\
5981 \\
11962\end{array}$ \\
\hline \multirow[b]{2}{*}{$R_{\mathrm{mor}}<1$} & 0.5 & -15.98 & $\begin{array}{c}1000 \\
2000 \\
5000 \\
10000\end{array}$ & $\begin{array}{c}840 \\
1680 \\
4201 \\
8402\end{array}$ \\
\hline & 0.25 & -31.42 & $\begin{array}{c}1000 \\
2000 \\
5000 \\
10000\end{array}$ & $\begin{array}{c}686 \\
1372 \\
3429 \\
6858\end{array}$ \\
\hline
\end{tabular}


TABLE 6: Percentage of change of formula comparison.

\begin{tabular}{|c|c|c|c|c|c|c|c|c|}
\hline \multirow{3}{*}{ Ref. } & \multirow{3}{*}{$E_{b}(\mathrm{MPa})$} & \multicolumn{6}{|c|}{ Percentage of change (Poc) \% } & \multirow[b]{3}{*}{5.00} \\
\hline & & \multicolumn{6}{|c|}{$R_{\text {mor }}$} & \\
\hline & & 0.25 & 0.50 & 1.00 & 2.00 & 3.00 & 4.00 & \\
\hline Brooks & \multirow{5}{*}{1000} & -29.58 & -12.28 & 0.00 & 7.53 & 10.29 & 11.73 & 12.61 \\
\hline Ciesielski & & -33.33 & -14.29 & 0.00 & 9.09 & 12.50 & 14.29 & 15.38 \\
\hline Matysek & & -31.86 & -13.48 & 0.00 & 8.45 & 11.59 & 13.24 & 14.24 \\
\hline Simulation & & -31.41 & -16.00 & 0.00 & 19.48 & 34.85 & 48.68 & 61.68 \\
\hline Formulation & & -33.34 & -16.99 & 0.00 & 19.79 & 34.60 & 48.34 & 62.71 \\
\hline Brooks & \multirow{5}{*}{2000} & -29.58 & -12.28 & 0.00 & 7.53 & 10.29 & 11.73 & 12.61 \\
\hline Ciesielski & & -33.33 & -14.29 & 0.00 & 9.09 & 12.50 & 14.29 & 15.38 \\
\hline Matysek & & -31.86 & -13.48 & 0.00 & 8.45 & 11.59 & 13.24 & 14.24 \\
\hline Simulation & & -31.43 & -15.98 & 0.00 & 19.62 & 35.05 & 48.94 & 61.98 \\
\hline Formulation & & -33.34 & -16.99 & 0.00 & 19.79 & 34.60 & 48.34 & 62.71 \\
\hline Brooks & \multirow{5}{*}{5000} & -29.58 & -12.28 & 0.00 & 7.53 & 10.29 & 11.73 & 12.61 \\
\hline Ciesielski & & -33.33 & -14.29 & 0.00 & 9.09 & 12.50 & 14.29 & 15.38 \\
\hline Matysek & & -31.86 & -13.48 & 0.00 & 8.45 & 11.59 & 13.24 & 14.24 \\
\hline Simulation & & -31.60 & -15.98 & 0.00 & 19.62 & 35.05 & 48.94 & 61.98 \\
\hline Formulation & & -32.23 & -16.99 & 0.00 & 19.79 & 34.60 & 48.34 & 62.71 \\
\hline Brooks & \multirow{5}{*}{10000} & -29.58 & -12.28 & 0.00 & 7.53 & 10.29 & 11.73 & 12.61 \\
\hline Ciesielski & & -33.33 & -14.29 & 0.00 & 9.09 & 12.50 & 14.29 & 15.38 \\
\hline Matysek & & -31.86 & -13.48 & 0.00 & 8.45 & 11.59 & 13.24 & 14.24 \\
\hline Simulation & & -31.43 & -15.98 & 0.00 & 19.65 & 35.05 & 48.93 & 61.98 \\
\hline Formulation & & -33.34 & -16.99 & 0.00 & 19.79 & 34.60 & 48.34 & 62.71 \\
\hline
\end{tabular}

TABLE 7: Gumaste data and experiment and numerical results.

\begin{tabular}{lcccccccccc}
\hline Ref. & \multicolumn{1}{c}{ Results } \\
& $\begin{array}{c}E_{b} \\
(\mathrm{MPa})\end{array}$ & $\begin{array}{c}E_{\mathrm{mor}} \\
(\mathrm{MPa})\end{array}$ & $v_{b}$ & $v_{\mathrm{mor}}$ & $\begin{array}{c}h_{b} \\
(\mathrm{~mm})\end{array}$ & $\begin{array}{c}l_{b} \\
(\mathrm{~mm})\end{array}$ & $\begin{array}{c}t_{b} \\
(\mathrm{~mm})\end{array}$ & $\begin{array}{c}t_{\mathrm{mor}} \\
(\mathrm{mm})\end{array}$ & $\begin{array}{c}E_{\mathrm{ex}} \\
(\mathrm{MPa})\end{array}$ & $\begin{array}{c}E_{\text {num }} \\
(\mathrm{MPa})\end{array}$ \\
\hline \multirow{3}{*}{ Gumaste et al. [3] } & 3370 & 8570 & 0.15 & 0.2 & 75 & 230 & 105 & 12 & 3317 & 4005 \\
& 3370 & 5450 & 0.15 & 0.2 & 75 & 230 & 105 & 12 & 3789 & 3684 \\
& 3370 & 7080 & 0.15 & 0.2 & 75 & 230 & 105 & 12 & 3677 & 3865 \\
\hline
\end{tabular}

TABLE 8: Comparison of equivalent elastic moduli based on Gumaste data $\left(E_{\text {mor }}>E_{b}\right)$.

\begin{tabular}{lccccc}
\hline$E_{\text {mor }} / E_{b}$ & $\begin{array}{c}\text { Numeric } \\
\text { Gumaste }\end{array}$ & Proposed & Brooks & Formula & Matystek \\
\hline 1.62 & 3.68 & 3.67 & 3.56 & 3.58 & 3.60 \\
2.10 & 3.87 & 3.86 & 3.64 & 3.67 & 3.69 \\
2.54 & 4.01 & 4.01 & 3.68 & 3.72 & 3.75 \\
\hline
\end{tabular}

other hand, the estimation using the proposed formula was $3-8 \%$ higher than the results of Ciesielski, (19), Brooks, (18), and Matystek, (17). Although numerical values obtained by Gumaste were very similar to those of the proposed formula, the experimental research is still required. To compensate for the lower brick strength in some countries, such as Indonesia and India, the proposed formula resulting from the investigation could be employed. The formula is appropriate for the calculation of the variable elasticity of low-quality masonry structures. In addition, the proposed formula is suitable for numerical applications on further large-scale masonry structures.

\section{Conclusions}

Most of the design formulae for calculating the equivalent elasticity of brick masonry structures are applicable only for the case where $E_{\text {mor }}<E_{b}$. The present study was focused on masonry structures with low-quality bricks; that is, $E_{\text {mor }}>E_{b}$. This paper presented numerical simulations to derive formulae for the equivalent elasticity of brick masonry structures. The accuracy of the formulae was discussed and verified by using experimental secondary data. The equivalent elasticity obtained using the newly developed formulae was estimated with high accuracy, resulting in a 


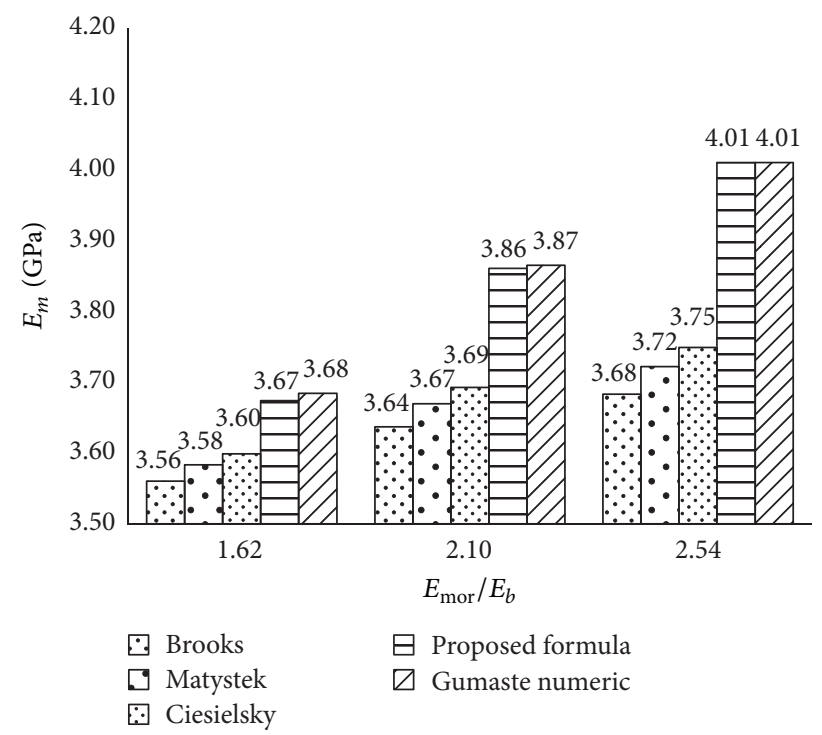

Figure 7: Comparison of equivalent elastic moduli based on Gumaste data $\left(E_{\text {mor }}>E_{b}\right)$.

discrepancy of less than $1 \%$ compared to the numerical results derived by Gumaste. The conclusions of this investigation are summarized as follows:

(i) The proposed formula is a new, simplified formula; we performed finite element (FE) simulations, adopting the homogenization technique. It can be used to calculate the equivalent modulus of elasticity of such brick masonry structures.

(ii) The conventional formula may underestimate the equivalent elasticity of the masonry structures made with mortar that has a higher modulus than bricks.

(iii) The proposed formula is applicable in various calculations of the equivalent elasticity of masonry structures. In particular, the formula can be suitable for the estimation of the equivalent elasticity of bricks with low elastic modulus. Furthermore, the proposed formula can be applied for bricks with high elastic modulus.

(iv) The equivalent elasticity estimated via the proposed formula increases in accordance with the increase in elastic modulus ratio of mortar.

(v) The proposed formula can be employed for masonry structures in countries that use bricks of low elastic moduli.

In further studies, it is suggested that the experimental research be extended, particularly to masonry structures that are composed of mortar with a higher modulus of elasticity than that of bricks.

\section{List of Symbols}

$\beta$ : Ratio of brick's elastic modulus to the mortar elastic modulus

$\delta$ : Geometric properties of cells
$E$ : Young's modulus

$E_{b}: \quad$ Modulus of elasticity of brick

$E_{m}$ : Modulus of elasticity of masonry

$E_{\text {mor }}:$ Modulus of elasticity of mortar

$\bar{E}_{x}$ : Average modulus of elasticity in $x$-direction calculation

$\bar{E}_{y}: \quad$ Average modulus of elasticity in $y$-direction calculation

$E_{x}: \quad$ Modulus of elasticity in $x$-direction calculation

$E_{y}:$ Modulus of elasticity in $y$-direction calculation

$E_{b}^{i}: \quad$ Modulus elastic moduli of brick in section $i$

$E_{m}^{i}:$ Modulus elastic moduli of mortar in section $i$

$\varepsilon_{x}: \quad$ Normal strain in $x$-direction

$\varepsilon_{y}: \quad$ Normal strain in $y$-direction

$\bar{\varepsilon}_{x x}: \quad$ Average normal strain in $x$-direction

$\bar{\varepsilon}_{y y}: \quad$ Average normal strain in $y$-direction

$\bar{\varepsilon}_{i j}:$ Average strain vector

$\varepsilon_{i j}:$ Strain vector

$G$ : $\quad$ Shear modulus

$\bar{G}: \quad$ Average equivalent shear modulus

$\gamma_{x y}: \quad$ Normal shear strain

$\bar{\gamma}_{x y}:$ Average normal shear strain

$h_{b}$ : Thickness of brick

$\xi: \quad$ Ratio of the height of bricks

$l_{b}$ : Long of brick

$\Omega: \quad$ Volume of RVE cell

Poc: Percentage of change

$\rho_{\text {mor }}:$ Volume ratio of mortar to the area of the cell

$R_{\text {mor }}:$ Ratio of mortar

$\bar{\sigma}_{i j}: \quad$ Average stress vector

$\sigma_{i j}: \quad$ Stress vector

$\sigma_{x}: \quad$ Normal stress in $x$-direction

$\sigma_{y}: \quad$ Normal stress in $y$-direction

$\bar{\sigma}_{x x}:$ Average normal stress in $x$-direction

$\bar{\sigma}_{y y}:$ Average normal stress in $y$-direction

$\theta: \quad$ Disparity value from geometric properties

$t_{m}$ : Thickness of mortar

$\tau_{x y}: \quad$ Normal shear stress

$\bar{\tau}_{x y}:$ Average normal shear stress

$u$ : $\quad$ Deformation in $x$-direction

$v: \quad$ Deformation in $y$-direction

$\bar{v}_{m}$ : Average of Poisson's ratio of masonry

$\bar{v}: \quad$ Average of Poisson's ratio

$v$ : Poisson ratio

$v_{x}: \quad$ Poisson ratio in $x$-direction calculation

$v_{y}$ : Poisson ratio in $y$-direction calculation

$\bar{v}_{x}: \quad$ Average Poisson ratio in $x$-direction calculation

$\bar{v}_{y}: \quad$ Average Poisson ratio in $y$-direction calculation

$w_{b}$ : Wide of brick.

\section{Additional Points}

Research highlights are as follows: (i) a proposed new formula for calculating the equivalent modulus of elasticity of masonry structures, built with low-modulus bricks; (ii) extensive finite element simulations by using representative volume elements (RVEs); (iii) verification of finite element 
models by using experimental data; and (iv) quantification of the elastic properties of lower-stiffness bricks used with higher stiffness mortar.

\section{Competing Interests}

The authors declare that they have no competing interests.

\section{References}

[1] G. Ma, H. Hao, and Y. Lu, "Homogenization of Masonry using numerical simulations," Journal of Engineering Mechanics, vol. 127, no. 5, pp. 421-431, 2001.

[2] A. Indra, S. Elfina, Nurzal, and H. Nofrianto, Development of Making Composite Clay/Silica Rha Application for Improfing the Quality of Red Brick in Order to Create Friendly Earthquake Building Materials, National Strategic Research, Bogor, Indonesia, 2013.

[3] K. S. Gumaste, K. S. N. Rao, B. V. V. Reddy, and K. S. Jagadish, "Strength and elasticity of brick masonry prisms and wallettes under compression," Materials and Structures, vol. 40, no. 2, pp. 241-253, 2007.

[4] P. Putri, "Quality Study in the reconstruction of brick houses that built after earthquake 2009 in Koto Tangah Sub-districtPadang," Procedia Engineering, vol. 95, pp. 510-517, 2014.

[5] Elhusna, A. S. Wahyuni, and A. Gunawan, "Performance of clay brick of Bengkulu," Procedia Engineering, vol. 95, pp. 504-509, 2014.

[6] Wisnumurti, S. M. Dewi, and A. Soehardjono, "Strength reduction factor $(\mathrm{R})$ and displacement amplification factor $(\mathrm{Cd})$ of confined masonry wall with local brick in Indonesia," Procedia Engineering, vol. 95, pp. 172-177, 2014.

[7] E. Basoenondo, Lateral load response of Cikarang brick wall structures-an experimental study [Disertasi], Build Environment, 2008.

[8] T. Paulay and M. J. Priestly, Seismic Design of Reinforced Concrete and Masonry Buildings, Wiley-Interscience, New York, NY, USA, 1992.

[9] I. Stefanou, K. Sab, and J.-V. Heck, “Three dimensional homogenization of masonry structures with building blocks of finite strength: a closed form strength domain," International Journal of Solids and Structures, vol. 54, pp. 258-270, 2015.

[10] F. Cluni and V. Gusella, "Homogenization of non-periodic masonry structures," International Journal of Solids and Structures, vol. 41, no. 7, pp. 1911-1923, 2004.

[11] A. Cecchi and R. Di Marco, "Homogenized strategy toward constitutive identification of masonry," Journal of Engineering Mechanics, vol. 128, no. 6, pp. 688-697, 2002.

[12] A. Zucchini and P. B. Lourenço, "A micro-mechanical model for the homogenisation of masonry," International Journal of Solids and Structures, vol. 39, no. 12, pp. 3233-3255, 2002.

[13] A. Rekik, S. Allaoui, A. Gasser, E. Blond, K. Andreev, and S. Sinnema, "Experiments and nonlinear homogenization sustaining mean-field theories for refractory mortarless masonry: the classical secant procedure and its improved variants," European Journal of Mechanics, A/Solids, vol. 49, pp. 67-81, 2015.

[14] G. N. Pande, J. X. Liang, and J. Middleton, "Equivalent elastic moduli for brick masonry," Computers and Geotechnics, vol. 8, no. 3, pp. 243-265, 1989.
[15] A. Anthoine, "Derivation of the in-plane elastic characteristics of masonry through homogenization theory," International Journal of Solids and Structures, vol. 32, no. 2, pp. 137-163, 1995.

[16] J. S. Lee, G. N. Pande, J. Middleton, and B. Kralj, "Numerical modelling of brick masonry panels subject to lateral loadings," Computers \& Structures, vol. 61, no. 4, pp. 735-745, 1996.

[17] A. Gabor, A. Bennani, E. Jacquelin, and F. Lebon, "Modelling approaches of the in-plane shear behaviour of unreinforced and FRP strengthened masonry panels," Composite Structures, vol. 74, no. 3, pp. 277-288, 2006.

[18] P. Lourenço, Computational Strategies for Masonry Structures, Delft University Press, Delft, The Netherlands, 1996.

[19] M. Mistler, A. Anthoine, and C. Butenweg, "In-plane and outof-plane homogenisation of masonry," Computers \& Structures, vol. 85, no. 17-18, pp. 1321-1330, 2007.

[20] G. Wang, S. Li, H.-N. Nguyen, and N. Sitar, "Effective elastic stiffness for periodic masonry structures via eigenstrain homogenization," Journal of Materials in Civil Engineering, vol. 19, no. 3, pp. 269-277, 2007.

[21] S. Pietruszczak and X. Niu, "A mathematical description of macroscopic behaviour of brick masonry," International Journal of Solids and Structures, vol. 29, no. 5, pp. 531-546, 1992.

[22] P. B. Lourenço, G. Milani, A. Tralli, and A. Zucchini, "Analysis of masonry structures: review of and recent trends in homogenization techniques," Canadian Journal of Civil Engineering, vol. 34, no. 11, pp. 1443-1457, 2007.

[23] P. Pegon and A. Anthoine, "Numerical strategies for solving continuum damage problems with softening: application to the homogenization of masonry," Computers and Structures, vol. 64, no. 1-4, pp. 623-642, 1997.

[24] R. Luciano and E. Sacco, "Homogenization technique and damage model for old masonry material," International Journal of Solids and Structures, vol. 34, no. 24, pp. 3191-3208, 1997.

[25] A. Anthoine, "Homogenization of periodic masonry: plane stress, generalized plane strain or 3D modelling?" Communications in Numerical Methods in Engineering, vol. 13, no. 5, pp. 319-326, 1997.

[26] A. Hendry, Structural Masonry, Macmillan, Basingstoke, UK, 1990.

[27] A. Mohebkhah, A. A. Tasnimi, and H. A. Moghadam, "Nonlinear analysis of masonry-infilled steel frames with openings using discrete element method," Journal of Constructional Steel Research, vol. 64, no. 12, pp. 1463-1472, 2008.

[28] P. B. Lourenço, J. G. Rots, and J. Blaauwendraad, "Continuum model for masonry: parameter estimation and validation," Journal of Structural Engineering, vol. 124, no. 6, pp. 642-652, 1998.

[29] G. Milani, P. Lourenço, and A. Tralli, "Homogenization approach for the limit analysis of out-of-plane loaded masonry walls," Journal of Structural Engineering, vol. 132, no. 10, pp. 1650-1663, 2006.

[30] R. Zavalis, B. Jonaitis, and P. Lourenco, "Analysis of bed joint influence on masonry modulus of elasticity," in Proceedings of the 9th International Masonry Conference, pp. 1-11, Guimarães, Portugal, July 2014.

[31] A. Drougkas, P. Roca, and C. Molins, "Numerical prediction of the behavior, strength and elasticity of masonry in compression," Engineering Structures, vol. 90, pp. 15-28, 2015. 


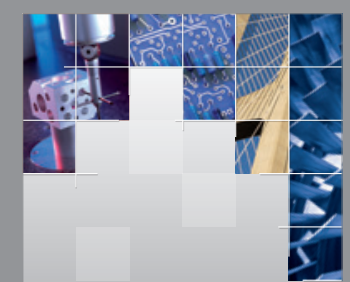

\section{Enfincering}
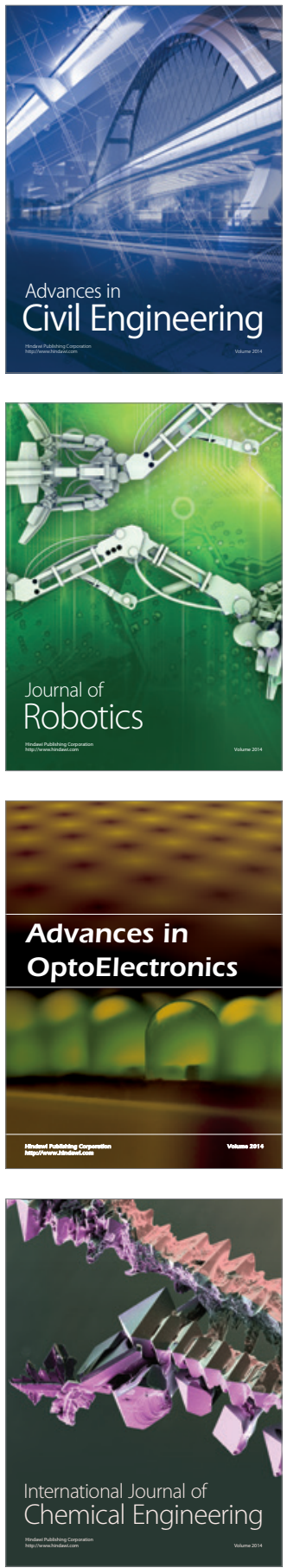

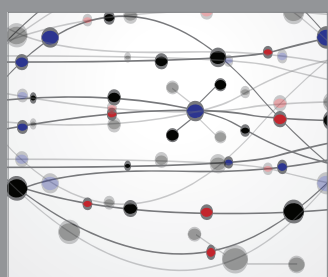

The Scientific World Journal

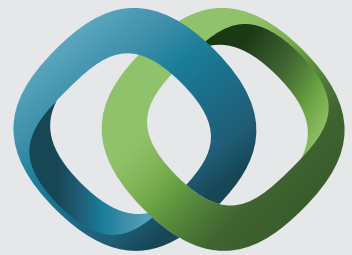

\section{Hindawi}

Submit your manuscripts at

https://www.hindawi.com
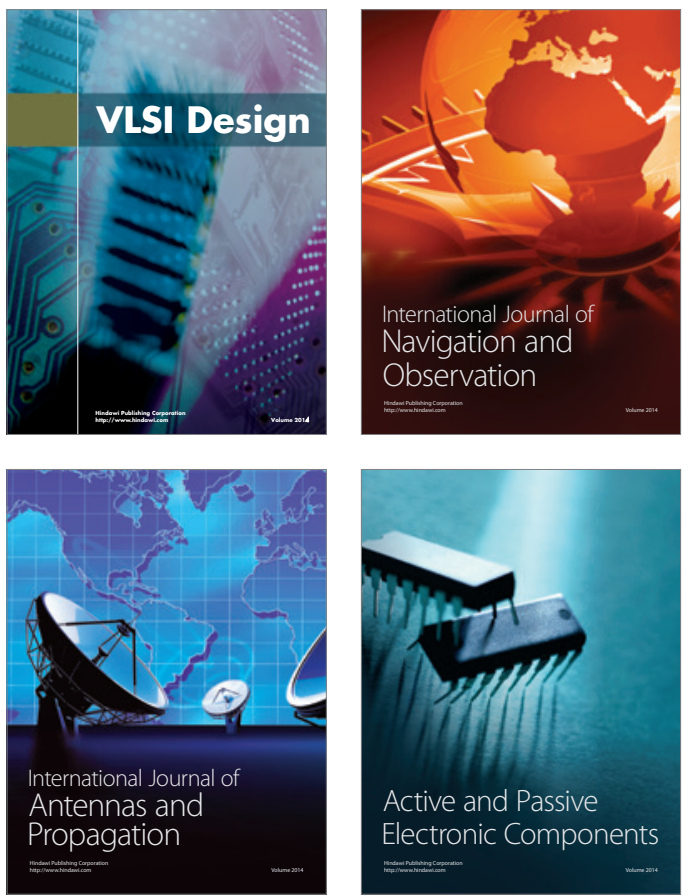
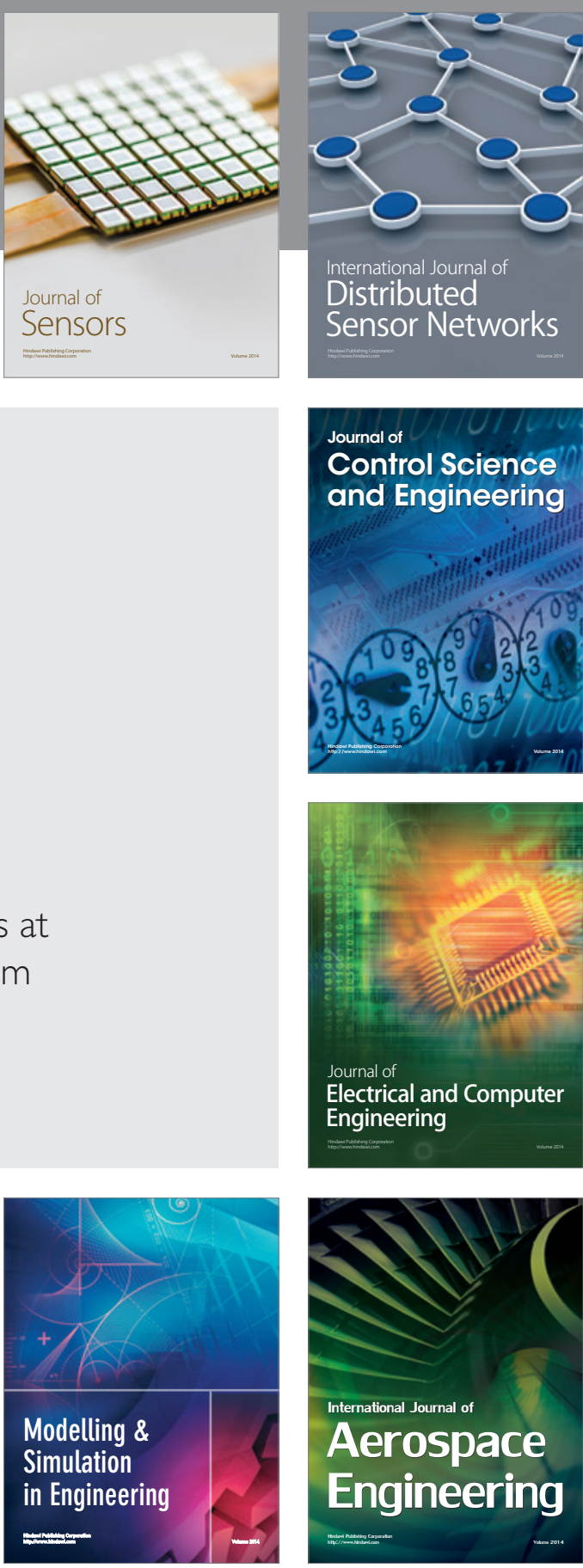

International Journal of

Distributed

Sensor Networks

$-$

Joumal of

Control Science

and Engineering
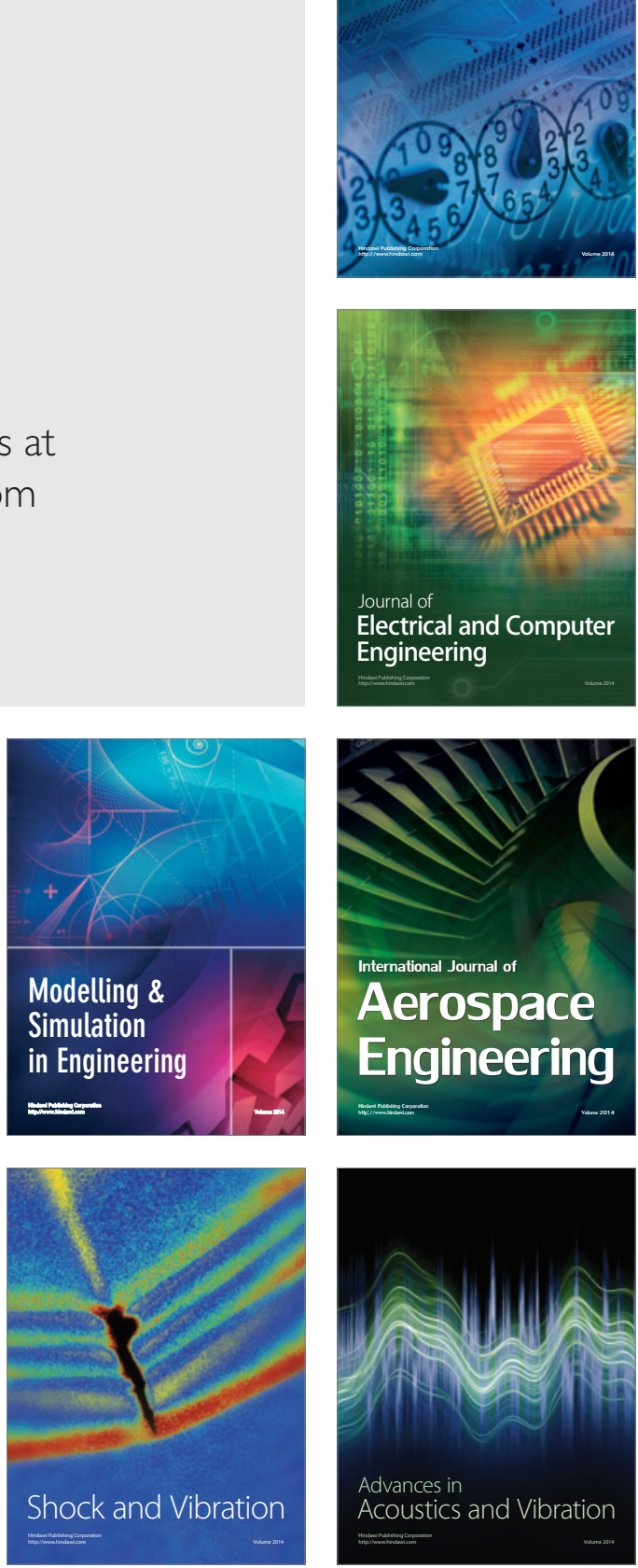